\title{
Understanding Leadership Challenges and Responses in Data-driven Transformations
}

\author{
Bing Windt \\ University of Amsterdam \\ bingwindt@gmail.com
}

\author{
Hans Borgman \\ University of Amsterdam \\ h.p.borgman@uva.nl
}

\author{
Chintan Amrit \\ University of Amsterdam \\ c.amrit@uva.nl
}

\begin{abstract}
The purpose of this study is to better understand challenges and typical responses of leadership in datadriven transformations. Increasingly organizations aspire to practices of data-driven decision making. In this context the transformational aspects transcend traditional change management processes and pose new and different challenges to leadership. To explore these challenges and typical responses we performed four in-depth case studies of organizations that are more mature in terms of their transformation towards a data-driven organization. Propositions derived from change management and digital transformation literature guide our exploration. Our findings help understand the key role of leadership in a data-driven transformation, particularly through (1) continuously communicating and explaining the value of being datadriven, (2) securing and managing critical resources, including data and analysts, and (3) creating a datadriven culture. Our study contributes to literature by combining insights from change management and data-driven transformations to better understand the dynamics of leadership in this context.
\end{abstract}

\section{Introduction}

Since the emergence of Big Data and sophisticated analytics, a vast majority of (larger) organizations has embraced initiatives in this area, with a significant and growing group reporting measurable results [1], [2]. Despite these successes at project level, only one third of companies is considering itself successful in adopting a data driven culture, and that number reportedly is not increasing [3], [4]. Such data-driven transformation goes beyond Big Data projects and involves transforming the culture and decision-making practices [5].

A critical factor in organizational change [6], and one that is in particular challenged in a data-driven context, is leadership [7]. According to a survey by NVP [8], executive leadership reports significant challenges in data-driven transformations, so much so that they are often among the first to give up [9]. Other studies identify new challenges in the data-driven context, such as availability of data, understanding the benefits of data, building analytical skills and anchoring these skills in the organizational culture [10], [11]. Generic theories of change management and digital transformation provide an understanding of the responses of leadership [12], [13]. In generic change processes leadership behavior typically starts with envisioning, then shifts to engaging, and lastly to empowering [14]. However, the new challenges of data-driven initiatives lead to reconsideration of our understanding of leadership responses in this context [15]. Scholars have attributed leadership as an important factor in creating a data-driven culture (DDC) [16] and ultimately for data-driven transformations [17].Yet, the challenges and responses of leadership in transformations towards data-driven organizations (DDO) have only been discussed at a conceptual level and need to be observed in practice [18], [19].

The purpose of this study is to better understand the challenges and typical responses of leadership in datadriven transformations. Performing a study in this direction is relevant for both academic and managerial practice. The following research question is formulated: How can we understand the challenges and typical responses of leadership in transformations towards data-driven organizations?

In this study a multiple case study design is employed, to uncover new and embedded insight. Four cases are studied by means of interviews. Data collection is guided by propositions derived from literature, which is explored in section 2. In section 3 the research methods are discussed followed by the fourth section providing an overview of the cases. A cross-case analysis is presented in section 5 . The findings are discussed in section 6 along with implications for practice and future research.

\section{Literature Review}

In this section the central concepts are discussed and propositions are formulated to guide the investigation and attain the purpose of this study. 


\subsection{Data-Driven Organizations}

Data-driven organizations are organizations in which decision making is enabled by evidence stemming from data - rather than intuition [7], [20]. This data is transformed into insight or action [21]. In order to produce insightful evidence from Big Data organizations need competencies in Data Analytics [22]. Organizations that are experienced in Data Analytics and Big Data use these as a competitive differentiator [23]. Additionally, DDOs use information and insight to outperform competitors and show an average stock value increase that is higher than industry peers [2], [24].

The path to becoming a DDO has been covered by terms as 'Datafication' [25] and Business Analytics Capability frameworks [10]. Through these concepts scholars express the importance of building organizational competencies to harness the value that Big Data offers [22]. One of the more used and cited frameworks for becoming a DDO is the DELTA model, which considers levels of data maturity [26], referring to the extent to which an organization is datadriven. Data Maturity, in this model, is measured by five phases, ranging from: analytically impaired to analytical competitors, and is explained by five dimensions: Data, Enterprise, Leadership, Targets and Analysts [16]. Other academics defined three key competencies for 'analytically sophisticated' organizations: information management, analytics skills and tools, and data-oriented culture [27]. Where Davenport \& Harris [16] emphasize a need for centralization of data and competencies to become data-driven, Kiron et al [27] create a distinction between 'specialized' and 'collaborative' paths to becoming more data-driven. This distinction is based on the approaches of specialized analytical expertise per line of business versus a centralized analytical expertise at the enterprise-level.

Ultimately, being a DDO means making better, data-driven decisions [5]. At the basis of data-driven decision making is insight and information [23], where organizations with more sophisticated analytical competencies focus more on insight rather than information [24].

However, not every organization is data-driven yet and in many cases organizational change is needed. Therefore, in the following section theories of organizational transformation are reviewed.

\subsection{Transformations towards DDOs}

A generic perspective on organizational transformation, or organizational change, is offered by Kotter [28], in which a uniform change process is described to follow eight steps. The latest adaptation of Kotter's work [12] combines the idea of continuous change with the concept of a so-called dual operating system, wherein a management-driven hierarchy is complemented by a network-like structure of individuals in realizing organizational change. Frameworks like these offer a generic view of organizational change [29]. More recently, models for processes of digital transformation combine staged interventions with ongoing drivers for change [30]. Considering that transformations towards DDOs are digitally enabled [20], models of digital transformation may prove insightful to understand organizations in this context [31].

However, the above mentioned frameworks might not cover all aspects of transformation towards DDOs, since additional challenges have arisen, such as: using analytics effectively for improved decision making, a lack of analytical skills in people, restrictions through existing IT platforms, accessing and processing data, creating an analytics strategy, and creating a corporate data culture [32]. Other scholars recognize challenges, in particular, for organizations in: talent management, technology and tools, decision making, organizational culture, data management, and leadership [7][10]. Comparing the sets of challenges, as stated above, the challenges of decision making, talent management, data, and culture emerge most frequent. Among these challenges, culture is covered in existing change management research [33], but is known to have additional characteristics in a data-driven context [10]. These additional challenges form the major differences between generic change management initiatives and data-driven transformation.

One of the cited challenges is leadership according to Brynjolfsson \& McAfee [7]. Leadership is by change management scholars recognized as an important factor in organizational change [6], and also for realizing the organizational benefits from datadriven decision making[17]. In the next section the investigation of the typical responses of leadership to challenges in transformations towards DDOs is continued.

\subsection{Responses of leadership in transformations towards DDOs}


Leadership is of critical importance to organizational change [14] and consists of establishing direction, aligning people, and motivating and inspiring [6]. Furthermore, leadership is considered one of the most important factors to determine the extent to which an organization becomes data-driven [16], [34] and a long-term driver of the organizational benefits of data-driven decision making [17]. In generic organizational change literature leadership is considered to display the following behaviors during a transformation: envisioning, engaging, and empowering [14]. Leadership is also considered to inspire and motivate people for organizational change [35] In data-driven transformation it is described that leadership sets clear goals, defines what success looks like, and asks the right questions [7].

As described before, the context of DDOs has additional challenges for organizations [7], [32]. These challenges can be translated into what is required of leaders in this context: communicating and explaining the benefits of data-driven decision making, and the acquisition and provision of required resources [10].

In the context of DDOs leadership is sometimes referred to as analytical leadership [18], which has a strong influence on culture, people, and resources in establishing analytical decision making, and may occur at multiple levels in the organization [16]. Additionally, it is seen as a leadership capability to instill a sense of passion for data-driven decision making in the organization [36].

Another field of study that is relevant to leadership in transformations towards DDOs is evidence-based management (EBM). EBM is a combination of culture and leadership-style where decisions are based on data rather than formal authority, reputation, intuition, and ad-hoc issues and where, if possible, statements are substantiated by evidence [37]. Deriving from EBM literature, leadership advocates, by communicating and explaining, the value of data-driven decision making within the organization [10]. In order to successfully communicate and explain these benefits, leaders need to become more analytical and develop a more analytical mindset [19]. An effective way of communicating the value of data-driven decision making is the use of success stories to illustrate sound practices [37]. Given that one of the prior identified challenges for organizations is realizing the value of data-driven decision making, and that in EBM literature leadership is a critical factor in communicating and explaining this value, the first proposition is determined:

Proposition 1: The first response of leadership to new challenges in the transformation towards datadriven organizations is communicating and explaining the value of data-driven decision making.
The leadership response of communicating and explaining serves to make the organization aware and understand the value of data-driven decision making, another response of leadership is to acquire and manage resources for data-driven initiatives [38]. In order to become data-driven organizations require quality data and data management [9], and adequate analytical tools [2]. The acquiring and accessing of quality data, one of the challenges for organizations [32], to a large extent determines the value of datadriven insights [39]. Enterprise data management raises additional issues, such as data privacy and new regulations [40].

Quality data is only a part of the story, since human resources are needed to process and interpret data [39], [41]. These are often referred to as analytics talent [32] or the analytical skills of the organization [27]. Difficulties exist with finding and hiring skilled analysts due to a scarcity of such skilled workers [39], [42]. Additionally, managing highly skilled and educated analysts poses its own challenges [43], given that analysts predominantly prefer to create solutions that work, while decision makers are primarily asking for advice [42]. Leadership instills trust in analysts and analytical techniques [18], provides analysts with autonomy [41], and aids analysts in connecting with decision makers to create and share knowledge and insight [38], [44]. Lastly, leadership is critical in securing the necessary financial resources to develop and train analysts [10]. This results in the second proposition:

Proposition 2: The second response of leadership to new challenges in a transformation towards datadriven organizations is securing and managing critical resources.

After communicating and explaining the value of data-driven decision making and subsequently securing the resources needed, there is the challenge of creating a data-driven culture (DDC) where evidence and insights from analytics are used to build arguments and make decisions [7], [32], [37]. Leadership has a strong influence on culture [16], in which information and insight are shared [23] and analysts and nonanalysts are able to learn from each other [21]. In such a culture, leadership has an open disposition towards data-driven insight and encourage evidence-based decision making from others [38]. Additionally, leaders works with analysts to learn what critical business questions can be addressed through data analytics, and learn what kind of questions can be answered by data [45]. As leaders display exemplifying behavior to establish a new culture and its values, some scholars press for a more extensive approach in establishing a DDC and really changing how people work and make decisions. In addition to 
demanding evidence, leadership in DDOs also examines the logic and assumptions behind decisions and questions, and the meaning of evidence [10], [37]. Therefore, some scholars argue that a shift should be made towards a more analytical mindset in culture [21]. To enable this shift, leadership needs an analytical mindset [19] and a basic understanding of data, analytical tools [23], and methods such as hypothesizing and testing [18], [45]. This leads to the formulation of the third proposition:

Proposition 3: The third response of leadership to new challenges in transformations towards datadriven organizations is creating a data-driven culture.

In this section we discussed the consecutive responses of leadership to challenges in transformations towards DDOs: (1) communicating and explaining the value of data-driven decision making, (2) securing and managing resources, and (3) creating a data-driven culture. This is a proposed deviation of established generic theories of organizational change, specifically for transformations towards DDOs. The proposed responses are described to accommodate the additional challenges that the context of DDOs offers.

\section{Research method}

A multiple case study approach has been selected to gain new insights and unveil unforeseen patterns [46] This should also allow for increasing the reliability and validity of this study [47]. Four cases are studied in-depth, comprising of four service firms with a business unit located in The Netherlands. These organizations all have an analytical competency for at least ten years, and the transformation to become a more DDO as a whole has been initiated in recent years.

The primary method for data collection is semistructured interviews and for additional data sources published interviews and documents were consulted. The interview guide is structured around the propositions as discussed in previous sections and allows for the investigation of emergent themes and unique case characteristics [47]. Within each case at least three, and in one case four, interviews were conducted with individuals in the positions: senior management, middle management, and data analyst or data scientist. These positions were chosen to create a complete image of the transformation. These three perspectives are selected to provide a comprehensive view of the cases in absence of the perspective of the $\mathrm{CDO}$ or highest leadership position, which is due to limited availability of those leaders. The interviews took between 30 and 60 minutes, with exception for the additional (fourth) interview. For the consistency of the study and the reliability of the data, only interviewees are selected that participate in the same change initiative. To the convenience of the interviewees, the interviews are conducted at the headquarters of the relative organization. Afterwards the interviews were analyzed and coded. Finally, the cases were analyzed and described per proposition and accompanied by relevant quotes of which an example is displayed in Table 1.

An additional note: twelve out of the thirteen interviews were conducted in Dutch, and one in English. Therefore, quotations from the Dutch interviews needed translation. A careful translation process and the consultation of a second reader are in place to prevent the loss of information and misinterpretation due to cultural and linguistic differences.

Table 1. Analysis case 3 proposition 1

\begin{tabular}{|c|c|c|}
\hline Proposition & Stance \& Position of Firm & Quotes \\
\hline $\begin{array}{l}\text { The first } \\
\text { leadership } \\
\text { response to new } \\
\text { challenges in the } \\
\text { transformation } \\
\text { towards DDOs is } \\
\text { communicating } \\
\text { and explaining the } \\
\text { value of data- } \\
\text { driven decision } \\
\text { making }\end{array}$ & $\begin{array}{l}\text { Senior leadership needs to } \\
\text { be aware of the potential } \\
\text { value of being data-driven. } \\
\text { A thorough understanding } \\
\text { of these benefits leads to } \\
\text { prioritization, and better } \\
\text { communication of the value } \\
\text { upwards and to the rest of } \\
\text { the organization. Making } \\
\text { the benefits of data-driven } \\
\text { understandable for and by } \\
\text { leadership is ideally done } \\
\text { by creating use cases. }\end{array}$ & $\begin{array}{l}\text { "Creating use cases that have } \\
\text { impact - that need not be } \\
\text { highly technical but need to } \\
\text { speak to the imagination or } \\
\text { solve a problem" } \\
\text { "Use cases are ideal ways for } \\
\text { leaders to explain the uses of } \\
\text { data \& analytics" } \\
\text { "Use cases I have made with } \\
\text { my team and simply new } \\
\text { good insight lead to other } \\
\text { leaders in the organization to } \\
\text { recognize our value" }\end{array}$ \\
\hline
\end{tabular}

Table 2: Case study overview

\begin{tabular}{|l|l|l|c|}
\hline $\begin{array}{l}\text { Case } \\
\text { \# interviews }\end{array}$ & $\begin{array}{l}\text { Reporting structure of } \\
\text { leadership }\end{array}$ & $\begin{array}{l}\text { Location of data \& } \\
\text { analyst organization }\end{array}$ & $\begin{array}{l}\text { Data } \\
\text { maturity } \\
\text { phase }\end{array}$ \\
\hline $\begin{array}{l}\text { 1. Elsevier } \\
\text { (3) }\end{array}$ & CDO, reports to CEO & $\begin{array}{l}\text { Central analyst team, } \\
\text { local data }\end{array}$ & 3 \\
\hline $\begin{array}{l}\text { 2. KLM } \\
(3)\end{array}$ & $\begin{array}{l}\text { Manager data within } \\
\text { digital transformation } \\
\text { team, reports to EVP }\end{array}$ & $\begin{array}{l}\text { Local analyst team, } \\
\text { local data }\end{array}$ & 3 \\
\hline $\begin{array}{l}\text { 3. KPN } \\
(4)\end{array}$ & $\begin{array}{l}\text { EVP D\&A, reports to } \\
\text { executive board }\end{array}$ & $\begin{array}{l}\text { Central \& local } \\
\text { integrated analysts } \\
\text { team, centralized data }\end{array}$ & 4 \\
\hline $\begin{array}{l}\text { 4. Vivat } \\
\text { (3) }\end{array}$ & $\begin{array}{l}\text { B.U. director reports to } \\
\text { executive level }\end{array}$ & $\begin{array}{l}\text { Local analyst team, } \\
\text { local Data }\end{array}$ & 3 \\
\hline
\end{tabular}

\section{Cases}

In the tables 2 and 3 general characteristics of the cases are displayed. In section 5 a general description to the cases is provided followed by a cross-case analysis to provide additional insights and compare findings per case, using interview quotations.

\section{Cross-case analysis}

Prior to performing the cross-case analysis a general description of the cases is provided in accordance with table 3 . 
Table 3: Cross-case analysis

\begin{tabular}{|l|l|l|c|l|l|l|l|}
\hline Case & Industry & $\begin{array}{l}\text { Start date } \\
\text { transformation }\end{array}$ & $\begin{array}{l}\text { Data } \\
\text { maturity } \\
\text { level }\end{array}$ & $\begin{array}{l}\text { Specialized vs. } \\
\text { collaborative } \\
\text { analytics }\end{array}$ & $\begin{array}{l}\text { Leadership challenge: } \\
\text { explaining value of data- } \\
\text { driven (response below) }\end{array}$ & $\begin{array}{l}\text { Leadership challenge: } \\
\text { securing and managing } \\
\text { resources (response below) }\end{array}$ & $\begin{array}{l}\text { Leadership challenge: } \\
\text { creating a data-driven } \\
\text { culture (response below) }\end{array}$ \\
\hline 1. Elsevier & Publishing & Jun. 2017 & 3 & Collaborative & $\begin{array}{l}\text { Through selected critical } \\
\text { projects. }\end{array}$ & $\begin{array}{l}\text { Access data and quality } \\
\text { analysts }\end{array}$ & Training and development \\
\hline 2. KLM & Aviation & Jan. 2016 & 3 & Specialized & $\begin{array}{l}\text { By providing operational } \\
\text { insight }\end{array}$ & $\begin{array}{l}\text { Access data and secure } \\
\text { budgets }\end{array}$ & $\begin{array}{l}\text { Define KPIs and } \\
\text { integrated teams }\end{array}$ \\
\hline 3. KPN & Telecom & Dec. 2015 & 4 & Collaborative & $\begin{array}{l}\text { By creating and sharing use } \\
\text { cases. }\end{array}$ & $\begin{array}{l}\text { Access data and integrate } \\
\text { analysts }\end{array}$ & $\begin{array}{l}\text { Challenge people and } \\
\text { evidence }\end{array}$ \\
\hline 4. Vivat & $\begin{array}{l}\text { Financial } \\
\text { Services }\end{array}$ & Jul. 2016 & 3 & Specialized & $\begin{array}{l}\text { Through the effect on profit } \\
\text { and loss }\end{array}$ & $\begin{array}{l}\text { Integrate and empower } \\
\text { analysts }\end{array}$ \\
\hline
\end{tabular}

The four cases concerned organizations that have been developing an analytical competency for at least ten years, contributing to the data maturity. In recent years these organizations started initiatives to increase the overall extent of data-driven decision making. These initiatives are in all cases initiated by the executive board or the CEO, and accordingly in three cases the highest-ranking leadership position concerned with the data-driven transformation reports directly to the executive board or CEO. Three of the organizations are in the third stage of the data maturity model, having so-called analytical aspirations. One organization is in the fourth stage being a so-called analytical company [16]. Given the focus on centralization for data and analytical competencies in the data maturity approach, also another approach is consulted, comprising of a specialized versus a collaborative path to analytical competencies [27]. Two cases are identified as having a more specialized approach, which allows for the development of deep analytics expertise within a line of business. The other two cases displayed collaborative characteristics in central data management and creating platforms to share insight. This general description of the cases serves to provides context for the following cross-case analysis.

In the following section a cross-case analysis is performed. In this analysis findings from each case are compared for each proposition to ultimately address the propositions and research question [47]. The analysis is aided by existing literature and direct quotations of interviewees to increase reliability and abstain from subjective interpretation [47].

\subsection{P1: Communicating and explaining value}

This section highlights the first response of leadership to challenges in transformations towards DDOs comprising of communicating and explaining the value of data-driven decision making. In case 2, regarding KLM, one of the interviewees clearly stated that "leadership is important in recognizing the value [of data] and communicating this to the rest of the organization". In the cases of Elsevier, KPN, and Vivat the this was expressed as well.

In the fourth case, Vivat, one interviewee stated: "if you don't have a manager or executive that sees and communicates the benefits, then you will not make it as an organization". In the third case, KPN, one interviewee said about the central data and analytics department: "Our leader has advocated our value and eventually established our position as an equal business unit and partner". One of the interviewees of the first case, Elsevier, stated: "we have periodical conferences with the SVPS to share experiences, discuss issues with data and also how to understand and explain the value of data", referring to leaders communicating and explaining the value of data to each other.

Furthermore, to be able to communicate and explain the value of data-driven decision making leaders need to be able to understand this themselves [10]. When asked whether or not leadership in a datadriven context needs deep an analytical skills and quantitative knowledge, one interviewee from Elsevier responded: "I think it is easier if one understands basic graphs and numerical information, but [the leader] doesn't know anything about modelling and programming". This is reaffirmed in the other cases, among that of KPN: "Leaders should at least have affinity with analytics. But they do not need to know everything about it - because that is why we are there as analytics team". However, understanding the value of data is not an ability that all leaders possess by default, as one interviewee from KLM stated: Leadership in our organization still really needs to learn a lot, when we speak about data".

How then do leaders learn to understand the value of data and learn to effectively communicate and explain this? The use of success stories as an effective means of communicating and explaining the benefits [37] is a recurring theme in all cases. In three of the cases, Elsevier, KLM, and KPN, this concept was referred to as: "use cases". In those organization, interviewees indicated use cases as an effective means of aiding leaders in understanding the value of data, but 
also in communicating and explaining this value to others in the organization. As stated by an interviewee of KPN: "Use cases are ideal ways for leaders to explain the uses of data \& analytics" One interviewee from Elsevier, stated: "We created use cases to communicate the value of data analytics". In the words of one interviewee of KPN: "Creating use cases that have impact - that need not be highly technical but need to speak to the imagination or solve a problem of the organization". In the same case, about the effects of employing use cases, one interviewee stated: "Use cases I have made with my team and simply good new insight lead to other leaders in the organization to recognize the value".

One interviewee from KLM even stated on the importance of use cases: "One of our greatest challenges is the absence of data use cases in the airline industry. We simply do not know yet what data can do for us", indicating the absence of industry level use cases as a disadvantage. According to an interviewee from Elsevier use cases can also be used as justification for the value of data-driven: "After some time you need to be able to prove your value". To conclude with a statement of an interviewee from KLM, regarding the leadership response of explaining: "Leadership is really important for helping others belief in the value of data. And they should give an example".

\subsection{P2: Securing and managing resources}

Organizations transforming towards data-driven need a number of resources: quality data, analytical people, and necessary budgets. These resources are often only provided after the value of data-driven decision making is sufficiently explained. One interviewee of KLM stated: "Leadership should be aware what we have in terms of data, what we can and can't do in terms of people, for what we have the resources, and how to manage these". In this section the need for respective resources and the leadership response of securing and managing these is discussed.

First, data-driven decision making begins with data, being high quality data that is accessible and available in the right format [16]. According to one interviewee from the Elsevier case: "[the leader] needs to understand what is needed in terms of data". An individual from KLM stated: "Leaders should be aware of what data we have and need". In the case of Vivat one interviewee stated: "[the leader] sees our need and is constantly seeking for new data sources", regarding the need for data that analysts have. In the Elsevier case, an interviewee stated: "it is getting better but not all data is centrally warehoused and therefore not accessible" and continues regarding leadership: "our leader needs to understand what data [analysts] need, to be able to acquire it”.

Second, leadership acquires and manages analytical people. This refers to individuals in roles of data analysts and data scientists. A first challenge for leadership is acquiring and keeping analysts. One interviewee from KPN stated: "the labor market is small, therefore it is key to find and retain skilled analysts". Another interviewee from Elsevier said: "It is difficult to find analysts, thus we must strive to keep them". These statements regard to the limited availability of analytically skilled workers. Concerning the retention of analysts an interviewee from KPN states: "leaders should have a focus for developing analysts to keep them interested". An interviewee from the Elsevier case adds to this by stating: "analysts should have the ability to receive training and develop their skills, and also have clear career opportunities within the organization". These last two statements relate to the ideas of growing and nurturing your analysts to retain them [40]. Additionally, leadership should be able to manage analysts by providing them with a sense of autonomy and allowing them to develop new analytical tools and use discovery analytics [38], or as stated by one interviewee from Vivat: "A leader should be able to recognize good analysts and their added value and then allow them to work freely and design their own jobs". Also, in the case of Vivat, leadership is stated to: "position people where they are of most value". Lastly, in the KPN case an interview stated: "Leadership is important to keep clear of too much distraction for analysts by business that withholds them from doing objective analysis".

Third, leadership acquires and manages financial resources. Leadership realizes this by first explaining the value of data-driven decision making and then presenting a business case that represents the investments and results. As stated by an interviewee from KLM: "In our low-margins business it is really important to have a solid business case to acquire the necessary resources". Additionally, "an interviewee from the Elsevier case stated: when a leader understands the value of data [the leader] is also better able to communicate this and acquire budgets.", indicating a clear link between the responses of explaining the value of data-driven and acquiring budgets. Regarding the managing of financial 
resources an interviewee from Elsevier stated: "balancing resources and prioritizing projects is a critical aspect".

Lastly, only after explaining the value of datadriven decision making securing resources becomes relevant. Furthermore, leaders need to understand the value of data-driven decision making first, before they can manage data, analysts, and financial resources effectively [10].

\subsection{P3: Creating a data-driven culture}

This section describes the third response of leadership to challenges in data-driven transformations: creating a DDC. Leadership is a strong influencer of culture, and does this by exemplifying behavior, and by conveying norms and values [16], [35]. Regarding creating a DDC, one interviewee in the case of Vivat stated: "[the leader] is important for creating culture and giving people freedom. We need to show why we do things as we do them in a safe and informal environment. Even more important than having data, logistics and so on". In the case of Elsevier one interviewee stated: "Building a culture for data-driven is important to build capabilities and help people learn". An interviewee in the Vivat case stated: "A leader should create a platform for people to ask sometimes dumb questions", referring to an organizational culture wherein nonanalytical individuals are able to consult with analysts and to learn.

In some organizations individuals proved reluctant to transform towards a DDC. As one interviewee from KLM stated: "In our business managers often act on gut feeling - intuition - because of the ad hoc and highly unpredictable nature. We currently do not have the belief that data can solve these problems of variability" and continued with: "Our managers are more occupied with daily issues - and less with managing by fact. Sort of a fire-fighting mentality", addressing the issues regarding perceived value of data-driven decision making and a lack of time and focus to implement this. In the case of Elsevier this is mentioned in the "art vs. science" paradigm in the publishing industry, as stated by one of the interviewees: "In the publishing business we have the classical discussion of art vs. science. Who is the better publisher? He or she that knows each author personally or the one that has analytic insight in a huge number of authors and publications?" signifying two opposing views that are reflected in culture.
To accommodate the creation of a DDC, in many organizations analysts are integrated in business teams to work on products or solutions. In the KLM case one interviewee stated: "senior management requires the cooperation of analysts in each improvement project, and even has re-located the analysts team to our office". An interviewee from KPN stated: "[a leader] leads the way by integrating teams and departments and working data-driven by hypothesizing and testing". Integrating teams as a means to promote datadriven decision making is mentioned by an interviewee from Vivat: "Hypothesis projects or other ideas start with the analysts and the product managers together". In order for analysts to contribute to the creation of a DDC, leadership provides them with a sense of freedom and empower them to educate and develop the organization, as stated by one interviewee from the Vivat case: "A leader needs to provide analysts with freedom to create their own job and actively involve them with others in the organization". An interviewee from KLM stated: "when a manager does not see the value of data, the specialists [analysts] should show this to them", and another interviewee in the same case stated: "I think it is the world on its head in that sense. They [analysts] have to take their leaders and the rest of the organization by the hand and teach them literacy in terms of data". These statements refer to the crucial role of analysts in creating a DDC reflecting the idea of a networked organization [12] wherein individuals in key positions, in this case analysts, work to establish organizational change. As indicated by the quotations the analysts also need to be empowered by leadership, in providing them with the tools and resources necessary, but also for analysts and data-driven decision making to be taken seriously leadership needs to endorse their involvement in project teams and decision-making processes.

However, there is an added difficulty in working with and depending on analysts in building a culture. Analysts have a preference for building their own tools and analytical models from the ground up, and create sound insights and advice [42], as stated by an interviewee from the KPN case: "Leadership is important to keep clear of too much distraction for analysts by demanding business questions that withhold them from doing objective analyses". According to an interviewee from Vivat, analysts are "highly skilled and intelligent individuals, who do not need management on the content of their job", but there is a role for leaders in "helping these somewhat 
more introvert individuals connect and share their ideas with others in the organization".

Additionally, when creating a DDC, leaders demand from individuals to base their decisions on evidence [37]. An interviewee from Vivat emphasizes this by stating: "A leader should take the lead and should keep asking for evidence when making decisions". In the KLM case one interviewee stated: "Leadership at the business unit level is really important in keeping everyone on track, asking for fact-based arguments, and challenging statements and claims. This goes beyond leading by example, as one interviewee from KPN continues: "Leaders should keep challenging their teams to test their assumptions". An interviewee from Vivat stated: "Leaders should stimulate a positive critical, investigating attitude, just checking the boxes is not enough" indicating that leaders should actively stimulate a DDC. In order to challenge their people and their evidence leaders need an analytical mindset and a basic understanding of analytics and data, as stated by an interviewee from the KPN case: "leaders do not need to get into specifics and know all the details of modelling - but they need to be able to do interpretation, seeing graphs and data, and they can understand and challenge what is happening here".

Another instance in the cases how leaders are creating a DDC, is by employing performance indicators (referred to as KPI) and real-time dashboards. According to an interviewee in KLM these measures allow for "real-time monitoring of processes and project performance and informed decision making". As stated by another interviewee from KLM: "It can really help to create an overview out of the data that displays which KPI's are going well and which are not. This makes it really concrete". Quantified performance measures and targets may contribute to a more data-driven mindset in the organization [24].

To conclude on leadership creating a DDC with a quotation of an interviewee in KPN: "Ultimately, for leaders there is a responsibility to raise the knowledge level of the organization in a broad sense and to increase the adoption level of analytics".

Lastly, regarding the sequence of the three responses of leadership to the new challenges: the value of data-driven decision making needs to be explained before data, analysts, and resources are provided. Then, after acquisition and managing of these resources, in particular data and analysts, an organization can proceed with creating a DDC.
In the following section the findings and directions for future research are discussed.

\section{Discussion and Conclusions}

Our findings support the propositions that in a transformation towards DDOs the observed typical responses of leadership are (1) to communicate and explain the value of data-driven decision making, (2) to acquire and manage critical resources, and (3) to create a data-driven culture. This addresses the research question: How can we understand the challenges and typical responses of leadership in transformations towards data-driven organizations?

To the first proposition regarding the response of communicating and explaining the value of datadriven decision making we have found support in all four cases. Additionally, the cases offer examples and practices for this response. Proposition two, regarding the response of securing and managing resources, received support from evidence from cases one, two and three, but only limited support from case four. Despite this all organizations have indicated challenges in data and talent management. The third proposition, concerning the leadership response of creating a data-driven culture, is supported by all four cases. Our supported findings, in combination with the consulted literature, form a basis to suggest further exploration and testing of these propositions in future research.

The implications of our results are threefold. First, our results provide a descriptive account based on four in-depth case studies to help understand the new challenges and typical responses of leadership in datadriven transformation. Our approach combines literature from the disciplines of change management and data-driven transformation providing a contribution to academia.

The second implication highlights the leadership response of communicating and explaining the value of data-driven decision making. This is critical for the success of transformations towards data-driven [27] and leaders need a good understanding of this value [10]. Effective means for understanding and communicating the value are use cases [37], being concrete and contextual examples of applications of data-driven insight.

Third, the acquisition and management of resources such as data, analysts and budgets depend strongly on the effectiveness of a leader explaining the value of being data-driven. The acquisition of relevant and quality data is not without issues and is key in enabling analysts to build insight. Analysts are difficult to find and retain due to the small labor market and require a fitting management style and a degree of 
autonomy. Nonetheless, analysts are critical in building a data-driven culture and transform the organization from the bottom-up [24].

One of the main limitations of our research is that we could interview only 3 personnel on average per organization. In our future research, we plan to conduct more in-depth case studies with a much larger sample size.

For future research, the supported propositions should be further studied to determine and refine the operational measures and ultimately quantify these. In addition, an investigation of more levels of management, such as C-level management could enrich the understanding of transformations towards data-driven organizations [18]. Moreover, as the academic field and the Big Data and analytics practice develop, more research and especially quantitative research should become within reach. Conclusively, longitudinal studies into organizations in a transformation towards data-driven will likely add more to our understanding of transformations towards data-driven organizations.

\section{References}

[1] R. Sharma, S. Mithas, and A. Kankanhalli, "Transforming decision-making processes: A research agenda for understanding the impact of business analytics on organisations," Eur. J. Inf. Syst., vol. 23, no. 4, pp. 433-441, 2014.

[2] K. Himmi, J. Arcondara, P. Guan, and W. Zhou, "Value Oriented Big Data Strategy: Analysis \& Case Study," Proc. 50th Hawaii Int. Conf. Syst. Sci., no. January, pp. 1053-1062, 2017.

[3] M. Gualtieri and N. Yuhanna, "The Forrester Wave ${ }^{\mathrm{TM}}$ : Big Data Hadoop," Forrester research, p. 15,2014 .

[4] T. H. Davenport and R. Bean, "Big Companies Are Embracing Analytics, But Most Still Don't Have a Data-Driven Culture," HBR Blog Network, 2018.

[5] E. Brynjolfsson, L. M. Hitt, and H. H. Kim, "Strength in Numbers: How Does Data-Driven Decisionmaking Affect Firm Performance?," SSRN Electron. J., 2011.

[6] J. P. Kotter, Force for change: How leadership differs from management. Simon and Schuster, 2008.

[7] A. McAfee and E. Brynjolfsson, "Big data: The Management Revolution.," Harv. Bus. Rev., no. October, pp. 1-9, 2012.
D. Kiron, “Organizational Alignment is Key to Big
Data Success," MIT Sloan Management Review's Big Ideas, vol. 54, no. 3, 2013.

[9] R. Bean, Good Data Governance for the Long Term (white paper). 2016.

[10] R. Cosic, G. Shanks, and S. Maynard, "A business analytics capability framework," Australas. J. Inf. Syst., vol. 19, pp. S5-S19, 2015.

[11] F. E. Bordeleau, E. Mosconi, and L. Santa-Eulalia, "Business Intelligence in Industry 4.0: State of the art and research opportunities," in Proceedings of the 51st Hawaii International Conference on System Sciences, 2018, vol. 9, no. January, pp. 3944-3953.

[12] J. Kotter, "Accelerate," Harv. Bus. Rev., no. November, pp. 1-17, 2012.

[13] K. Liere-Netheler, S. Packmohr, and K. Vogelsang, "Drivers of Digital Transformation in Manufacturing," in Proceedings of the 51st Hawaii International Conference on System Sciences |, 2018, pp. 3926-3935.

[14] D. A. Nadler and M. L. Tushman, "Beyond the charismatic leader: Leadership and organization change and California Management Review, 32 (2), 77-97 (Winter 1990)," Long Range Plann., vol. 23, no. 5, p. 133, 1990.

[15] M. S. Kart, "How to Take a First Step to Advanced Analytics.," Gartner Business Intelligence \& Analytics Summit, Gartner, 2015.

[16] T. H. Davenport and G. H. Harris, Competing on analytics: The new science of winning. Harvard Business Press, 2007.

[17] P. B. Seddon, D. Constantinidis, T. Tamm, and H Dod, "How does business analytics contribute to business value?," Thirty Third Int. Conf. Inf. Syst., pp. 1-17, 2012.

[18] A. Abbasi, "Big Data Research in Information Systems: Toward an Inclusive Research Agenda," J. Assoc. Inf. Syst., vol. 17, no. 2, pp. 1-32, 2016.

[19] K. D. A. Carillo, "Let's stop trying to be 'sexy' preparing managers for the (big) data-driven business era," Bus. Process Manag. J., vol. 23, no. 3, pp. 598-622, 2017.

[20] J. Hausberg, K. Liere-Netheler, S. Packmohr, S. Pakura, and K. Vogelsang, "Digital Transformation in Business Research: A Systematic Literature Review and Analysis," in Proceedings of DRUID18, 2018.

[21] C. Holsapple, A. Lee-Post, and R. Pakath, "A unified foundation for business analytics," Decis. Support Syst., vol. 64, pp. 130-141, 2014. 
[22] M. Ghasemaghaei, S. Ebrahimi, and K. Hassanein, "Data analytics competency for improving firm decision making performance," J. Strateg. Inf. Syst., no. March, pp. 0-1, 2017.

[23] S. Lavalle, E. Lesser, R. Shockley, M. S. Hopkins, and N. Kruschwitz, "Big Data, Analytics and the Path From Insights to Value," MIT Sloan Manag. Rev., vol. 52, no. 2, pp. 21-32, 2011.

[24] T. H. Davenport and J. Harris, "Competing on Talent Analytics," Harv. Bus. Rev., vol. 88, no. 10, pp. 52-58, 2010.

[25] M. Lycett, “'Datafication': Making sense of (big) data in a complex world," Eur. J. Inf. Syst., vol. 22, no. 4, pp. 381-386, 2013.

[26] T. T. Tamm, P. Seddon, and G. Shanks, "Pathways to Value from Business Analytics," Icis, vol. 4, pp. 2915-2930, 2013.

[27] D. Kiron et al., "Analytics: The Widening Divide advantage through analytics," MITSloan Manag. Rev., pp. 1-21, 2011.

[28] J. P. Kotter, "Leading Change: Why Transformation Efforts Fail," Harv. Bus. Rev., no. June, 1995.

[29] K. E. Weick and R. E. Quinn, "Organizational Change and Development," Annu. Rev. Psycholgy, vol. 50, pp. 361-386, 1999.

[30] H. Heier, H. P. Borgman, and T. H. Hofbauer, "Making the most of IT governance software: Understanding implementation processes," Proc. Annu. Hawaii Int. Conf. Syst. Sci., pp. 1-11, 2008.

[31] R. Sharma, P. Reynolds, R. Scheepers, P. B. Seddon, and G. Shanks, "Business analytics and competitive advantage: A review and a research agenda," Front. Artif. Intell. Appl., vol. 212, pp. 187-198, 2010.

[32] R. Vidgen, S. Shaw, and D. B. Grant, "Management challenges in creating value from business analytics," Eur. J. Oper. Res., vol. 261, no. 2, pp. 626-639, 2017.

[33] Q. N. Huy and H. Mintzberg, "The Rhythm of Change," MIT Sloan Manag. Rev., vol. 44(4), no. 79, pp. 43-53, 2003.

[34] P. Barth and R. Bean, "Quick Wins Help Avoid Culture Obstacles on the Path to Value," MIT Sloan Manag. Rev., vol. 53, no. 2, pp. 1-4, 2011.

[35] W. H. Bommer, G. . Rich, and R. S. Rubin, "Changing attitudes about change: longitudinal effects of transformational leader behaviour on employee cynicism about organisational change," J. Organ. Behav., vol. 26, no. 7, pp. 733-753, 2005.
[36] G. H. Laursen and J. Thorlund, Business analytics for managers: Taking business intelligence beyond reporting. John Wiley \& Sons, 2016.

[37] J. Pfeffer and R. I. Sutton, "Evidence-Based Management," Harv. Bus. Rev., vol. 84, no. 1, pp. $1-12,2006$.

[38] R. Cosic, G. Shanks, and S. Maynard, "Towards a business analytics capability maturity model," ACIS 2012 Locat. Locat. Locat. Proc. 23rd Australas. Conf. Inf. Syst. 2012, pp. 1-11, 2012.

[39] S. Shah, A. Horne, and J. Capellá, "Good data won't guarantee good decisions," Harv. Bus. Rev., vol. 90, no. 4, pp. 23-26, 2012.

[40] S. Fosso Wamba, S. Akter, A. Edwards, G. Chopin, and D. Gnanzou, "How 'big data' can make big impact: Findings from a systematic review and a longitudinal case study," Int. J. Prod. Econ., vol. 165, pp. 234-246, 2015.

[41] H. Ekbia et al., "Big data, bigger dilemmas: A critical review: Big Data, Bigger Dilemmas: A Critical Review," J. Assoc. Inf. Sci. Technol., vol. 66, no. 8, pp. 1523-1545, 2015.

[42] T. H. Davenport and D. J. Patil, "Data scientist: the sexiest job of the 21 st century: meet the people who can coax treasure out of messy, unstructured data," Harv. Bus. Rev., vol. 90, no. October, pp. 70-77, 2012.

[43] P. Barth, R. Bean, and T. H. Davenport, "How " Big Data' Is Different," MIT Sloan Manag. Rev., vol. 54, no. 1, pp. 43-46, 2012.

[44] E. Mosconi and M. C. Roy, "Making Links between Knowledge Management and Organizational Performance," Int. Bus. Res., vol. 6, no. 9, pp. 68-76, 2013.

[45] P. Barth and R. Bean, "Get the Maximum Value Out of Your Big Data Initiative," HBR Blog Network, 2013.

[46] R. K. Yin, Qualitative research from start to finish. Guilford Publications, 2015.

[47] K. M. Eisenhardt, "Building Theories from Case Study Research Published by : Academy of Management," vol. 14, no. 4, pp. 532-550, 1989. 